\title{
Wilt, Crown, and Root Rot of Common Rose Mallow (Hibiscus moscheutos) Caused by a Novel Fusarium sp.
}

S. L. Lupien and F. M. Dugan, Western Regional Plant Introduction Station, United States Department of Agriculture-Agricultural Research Service (USDA-ARS), Pullman, WA 99164; K. M. Ward, Washington State University Plant Pest Diagnostic Clinic, Pullman 99164; and K. O'Donnell, Mycotoxin Prevention and Applied Microbiology Research Unit, USDA-ARS National Center for Agricultural Utilization Research, Peoria, IL 61604

\begin{abstract}
A new crown and root rot disease of landscape plantings of the malvaceous ornamental common rose mallow (Hibiscus moscheutos) was first detected in Washington State in 2012. The main objectives of this study were to complete Koch's postulates, document the disease symptoms photographically, and identify the causal agent using multilocus molecular phylogenetics. Results of the pathogenicity experiments demonstrated that the Fusarium sp.

could induce vascular wilt and root and crown rot symptoms on H. moscheutos 'Luna Rose'. Maximum-likelihood and maximum-parsimony phylogenetic analyses of portions of translation elongation factor 1- $\alpha$ and DNA-directed RNA polymerase II largest and second-largest subunit indicated that the Hibiscus pathogen represents a novel, undescribed Fusarium sp. nested within the Fusarium buharicum species complex.
\end{abstract}

Hibiscus moscheutos L. (rose mallow or crimson-eyed rosemallow) is a malvaceous perennial that is used extensively as a landscape ornamental throughout the United States. This shrubby, cold-hardy perennial is native to wetlands in the central and southeastern United States, with a range that extends into southern Ontario (http:// plants.usda.gov/java/). This species is the focus of recent management efforts (Environment Canada 2013) as well as research on propagation, genetics, and ecology (Hunter-Cario 2007; Klips et al. 2005; Kudoh and Whigham 2001). Many cultivars and hybrids have long been used in the ornamental landscape industry (Small 2004). Mature plants grow 0.6 to 2.4 meters tall, depending on the cultivar and environment, and produce several stems each year, with large flowers 10 to $25 \mathrm{~cm}$ in diameter (Winters 1970). Stems typically die back in the fall, with new growth emerging from the crown in the spring.

Hibiscus is the third highest-ranking deciduous shrub within the United States, based on sales, with an estimated wholesale value of \$23.2 million annually (Boyd and Cheatham 2004). Given its value to the ornamental industry and the long history of plant breeding efforts focused on developing resistant cultivars and hybrids, emergent diseases of $H$. moscheutos could have important implications for the industry. Therefore, the present research was initiated following the discovery of a putatively novel crown rot and vascular wilt disease of several $H$. moscheutos cultivars in a Washington State landscape during 2012 and two subsequent years. Thus, the main focus of this research was to attempt to complete Koch's postulates on H. moscheutos 'Luna Rose', compare the disease symptoms induced by the Fusarium sp. on rose mallow with those elicited by a closely related species, Fusarium buharicum Jacz., on kenaf (H. cannabinus L.) (Gerlach and Scharif 1970; Scharif and Akhavizadegan 1967), and identify the Fusarium

Corresponding author: K. O’Donnell; E-mail: kerry.odonnell@ars.usda.gov

Mention of trade names or commercial products in this publication is solely for the purpose of providing specific information and does not imply recommendation or endorsement by the U.S. Department of Agriculture. USDA is an equal opportunity provider and employer.

Accepted for publication 6 October 2016.

This article is in the public domain and not copyrightable. It may be freely reprinted with customary crediting of the source. The American Phytopathological Society, 2017. sp. isolated from symptomatic rose mallow using genealogical concordance phylogenetic species recognition (Taylor et al. 2000).

\section{Materials and Methods}

Acquisition and identification of plant material. Specimens of six different cultivars of Hibiscus moscheutos ('Plum Crazy', 'Disco Belle', 'Southern Bell White', 'Flare Rose', 'Rainer Red', and 'Mighty Big Pink') plus an unknown cultivar exhibiting symptoms of crown rot were submitted to the Washington State University Plant Pest Diagnostic Clinic from a home landscape in Benton County, WA from 2012 through 2014. Southern Bell White was purchased at a garden center in Pasco, WA; Disco Belle in Kennewick, WA; Flare Rose and Mighty Big Pink in Wagoner, OK; and Rainer Red in Glencoe, MO; however, the distributor of Plum Crazy was unknown. Species identity of submitted material was confirmed by the landscape owner's purchase records and by comparison of specimens with online photographs and descriptions (http://plants.usda.gov/java/; http://www.missouribotanicalgarden.org). The specimens submitted included living green stems with wilted leaves; some plants had dark-brown to black cankers extending from the crown into the stem. Cankers occasionally bore salmon-colored sporodochia with typical Fusarium fusiform, multiseptate macroconidia. Roots of infected crowns showed various levels of rot that usually was restricted to smaller roots.

Fungal isolation and preservation. Tissue from stem and root lesion margins was excised and surface disinfested for 4 min in $0.5 \%$ sodium hypochlorite, rinsed with sterile water, and then transferred to petri dishes containing half-strength V8 juice (1/2V8) agar (Stevens 1974) amended with antibiotics (streptomycin sulfate and tetracycline hydrochloride at $50 \mu \mathrm{g} / \mathrm{liter}$ ). Single-spore colonies were obtained by touching a sporodochium growing on 1/2V8 agar with a sterile loop, streaking the sporodochial conidia onto fresh $1 / 2 \mathrm{~V} 8$, and then transferring single, well-isolated colonies onto fresh $1 / 2 \mathrm{~V} 8$ agar. Cultures were then incubated at ambient room temperature (approximately $24^{\circ} \mathrm{C}$ ) on $1 / 2 \mathrm{~V} 8$ agar without antibiotics. Singlespored colonies on 1/2V8 agar grown under near ultraviolet and cool white lighting produced little aerial mycelium but frequently formed concentric rings of salmon-colored sporodochia and abundant dark-blue to black sclerotia. Two representative strains per year collected in 2012, 2013, and 2014 were archived in the Western Regional Plant Introduction Station (WRPIS) culture collection, Pullman, WA in $15 \%$ glycerol at $-80^{\circ} \mathrm{C}$ and in the Agricultural Research Service Culture Collection (NRRL), Peoria, IL (Table 1).

Pathogenicity of isolates on $\boldsymbol{H}$. moscheutos. Plants for the pathogenicity experiment were reared from $H$. moscheutos Luna Rose seed 
(Swallow Tail Gardens, Santa Rosa, CA), which had been disinfested with $0.5 \%$ sodium hypochlorite solution for $2 \mathrm{~min}$ and rinsed in sterile water prior to germination in Sunshine number 5 potting mix. Plants were grown for 7 weeks and were approximately 15 to $20 \mathrm{~cm}$ tall when they were inoculated. Inoculum for the pathogenicity experiments was grown on 1/2V8 agar for 3 to 4 weeks for $12 \mathrm{~h}$ /day under combined cool white and near ultraviolet light at 21 to $24^{\circ} \mathrm{C}$. Conidia were gently washed from the surface of cultures with sterile water and quantified using a hemocytometer; then, sterile water was used to adjust the concentration to $1.0 \times 10^{5}$ and $5.0 \times 10^{5}$ conidia/ml for the first and second experiments, respectively. Each plant was punctured once on the stem just above the crown with a sterile 26-gauge needle to the depth of the needle bevel $(2.5 \mathrm{~mm})$. A sterile pipette tip was used to inoculate the wound site with $0.5 \times 10^{5}$ conidia in the first and $2.5 \times 10^{5}$ conidia in the second experiment. Negative controls were inoculated with sterile water. The negative controls (mockinoculated plants) were established using potting mix from exactly the same fresh bags of Sunshine mix 5 as the inoculated plants. For the initial experiment, plants were placed in plastic trays and sealed in plastic canopies to maintain humidity. Each canopy had a $46-\mathrm{cm}^{2}$ window at each end made of Miracloth (22- to 25- $\mu \mathrm{m}$ pore mesh; Calbiochem catalog number 475855) for ventilation. In the second experiment, each plant was placed in a tray and then covered with a Sun Bag (Sigma-Aldrich catalog number B7026) that had a single $4-\mathrm{cm}^{2}, 0.02-\mu \mathrm{m}$ pore mesh window. After the inoculated plants had been enclosed in Sun Bags for $72 \mathrm{~h}$, the bags were removed for the duration of the experiment.

Pathogenicity assays were conducted with the following three isolates: 2012-95 (= NRRL 66179), 2013-63 (= NRRL 66182), and 2014-53r (= NRRL 66184). The first experiment was initiated on 23 December 2014 in a WRPIS greenhouse using 24 plants randomly assigned to three inoculation treatments and a negative control. Each of the three treatments employed one of the three fungal isolates listed. The control was inoculated with sterile water. Each treatment and the control consisted of six plants (two replicates of three plants each). Plants were randomly assigned a treatment and position within the greenhouse canopies, using a random sequence function (https://www.random.org/). The experiment was repeated beginning on 6 August 2015 and conducted in a temperature-regulated growth room using the same experimental design and treatment application as the first trial. HOBO data loggers (Onset Computer Corporation, Bourne, MA) were used to record temperature and humidity within the greenhouse canopies and within the growth room. The greenhouse was supplied with $16 \mathrm{~h}$ of supplemental daytime lighting and the growth room with $16 \mathrm{~h}$ of artificial lighting. During the first experiment, the plastic canopy interiors within the greenhouse ranged from 8 to $12^{\circ} \mathrm{C}$ (nights) and 16 to $27^{\circ} \mathrm{C}$ (days). The growth room temperature ranged from 17.5 to $19.5^{\circ} \mathrm{C}$ (nights) and 24 to $26^{\circ} \mathrm{C}$ (days) during the second experiment.

Lesion diameter, plant height, and the presence or absence of disease symptoms were recorded 5.5 weeks postinoculation in the initial experiment and 2.5 weeks postinoculation in the second experiment. The maximum diameter of stem lesions was measured near the crown of the plant, or the wound site was measured in the absence of lesion development in the negative controls. Lesion margins (or the wound site in the absence of rot) were excised aseptically, surface disinfested for $2 \mathrm{~min}$ in $0.5 \%$ sodium hypochlorite solution, rinsed with sterile water, and then plated on $1 / 2 \mathrm{~V} 8$ agar amended with antibiotics for reisolation of the pathogen. The novel Fusarium sp. was reisolated from the inoculated wound sites but never from the mock-inoculated wound sites. To complete Koch's postulates, isolates recovered from plants used in the pathogenicity experiments were identified using a partial translation elongation factor $1-\alpha$ (TEF1) sequence.

Statistical analysis. Each of the three isolates is regarded as a treatment. Analysis of variance (ANOVA; to detect overall differences between treatments and the control), $t$ tests (to detect differences between individual treatments and the control), and general linear models (GLM; Fisher's least significant difference, model mean square error, to detect pairwise differences between treatments) were conducted in Systat 13 (Systat Software, Inc., Chicago).

Molecular phylogenetic identification of fungal isolates. Isolates were cultured in yeast-malt broth for 4 days and freeze dried overnight; then, a hexadecyltrimethyl-ammonium bromide (Sigma-Aldrich, St. Louis) protocol was used to extract total genomic DNA, as previously described (O'Donnell et al. 1998). Portions of the following three phylogenetically informative loci were polymerase chain reaction (PCR) amplified and sequenced following published protocols (O'Donnell et al. 2010, 2013): TEF1 and DNA-directed RNA polymerase II largest $(R P B 1)$ and second-largest $(R P B 2)$ subunits. Platinum Taq

Table 1. Isolates used in the phylogenetic analysis

\begin{tabular}{|c|c|c|c|c|}
\hline NRRL $^{a}$ & Equivalent number ${ }^{\mathbf{b}}$ & Fusarium spp. & Host, substrate & Geographic origin \\
\hline 13371 & CBS 796.70 & Fusarium buharicum Jacz. & Hibiscus cannabinus L. & Iran \\
\hline 13384 & CBS 189.34 & F. sublunatum Reinking & Soil & Costa Rica \\
\hline 13622 & FRC I-55 & F. lateritium Wollenw. & Ulmus sp. & Louisiana \\
\hline 20429 & ATCC 15662 & F. stilbioides Wollenw. & Coffee & Nyasaland \\
\hline 20472 & CBS 745.79 & F. sarcochroum (Desm.) Sacc. & Viscum album $\mathrm{L}$. & Switzerland \\
\hline 20897 & CBS 190.34 & F. sublunatum & Soil & Costa Rica \\
\hline 25488 & CBS 178.35 & F. buharicum & Gossypium sp. & Russia \\
\hline 36148 & CBS 109638 & F. buxicola Sacc. & Buxus sp. & Belgium \\
\hline 53998 & CBS 101734 & $\begin{array}{l}\text { F. cyanostomum (Sacc. \& Flageolet) O'Donnell } \\
\text { \& Geiser }\end{array}$ & Buxus sempervirens L. & France \\
\hline 54149 & JAS 481 & $\begin{array}{l}\text { F. torreyae T. Aoki, J. A. Smith, L. Mount, } \\
\text { Geiser and O'Donnell }\end{array}$ & Torreya taxifolia Arn. & Florida \\
\hline 66179 & WRPIS 2012-95 & Fusarium sp. & H. moscheutos L. Southern Belle White & Washington \\
\hline 66180 & WRPIS 2012-121 & Fusarium sp. & H. moscheutos Flare Rose & Washington \\
\hline 66181 & WRPIS 2013-62 & Fusarium sp. & H. moscheutos Mighty Big Pink & Washington \\
\hline 66182 & WRPIS 2013-63 & Fusarium sp. & H. moscheutos Plum Crazy & Washington \\
\hline 66183 & WRPIS 2014-53s & Fusarium sp. & H. moscheutos unknown cultivar & Washington \\
\hline 66184 & WRPIS 2014-53r & Fusarium sp. & H. moscheutos unknown cultivar & Washington \\
\hline- & F201114 & $\begin{array}{l}\text { F. zanthoxyli X. Zhou, T. Aoki, } \\
\text { K. O'Donnell \& Z. M. Cao }\end{array}$ & Zanthoxylum bungeanum Maxim. & China \\
\hline- & F201126 & $\begin{array}{l}\text { F. continuum X. Zhou, T. Aoki, K. O’Donnell } \\
\text { \& Z. M. Cao }\end{array}$ & Z. bungeanum & China \\
\hline
\end{tabular}

\footnotetext{
a Agricultural Research Service Culture Collection, Peoria, IL.

${ }^{\mathrm{b}}$ ATCC $=$ American Type Culture Collection, Manassas, VA; CBS = CBS-KNAW Fungal Biodiversity Center, Utrecht, The Netherlands; F = Northwest A\&F University, Shaanxi, China; FRC = Fusarium Research Center, Department of Plant Pathology, The Pennsylvania State University, University Park; JAS = Jason A.
} Smith, University of Florida, Gainesville; and WRPIS = Western Regional Plant Introduction Station, Pullman, WA. 
DNA polymerase (Invitrogen Life Technologies, Carlsbad, CA) was used for all PCR amplifications, amplicons were purified with Montage $_{96}$ filter plates (Millipore Corp., Billerica, MA), BigDye 3.1 Terminator reaction mix was used to sequence the amplicons, and sequencing reaction mixes were purified with BigDye Xterminator prior to running them on an $\mathrm{ABI} 3730$ genetic analyzer. $\mathrm{ABI}$ sequence chromatograms were edited with Sequencher 5.2.4 (Gene Codes Corp., Ann Arbor, MI) and then exported as three separate partitions. The $R P B 1$ and $R P B 2$ partitions lacked indels (insertions and deletions), and, therefore, were well aligned; however, MUSCLE (Edgar 2004) was used to align the indel-containing TEF1 partition. The NEXUS files were analyzed using maximum-likelihood (ML) (Zwickl 2006) and maximum-parsimony (MP) (Swofford 2003) methods as described by Crespo et al. (2016). BLASTn searches of GenBank (https://blast.ncbi.nlm.nih.gov/Blast.cgi), using the partial RPB1 and $R P B 2$ sequences as the queries, suggested that the $H$. moscheutos crown rot pathogen likely represented a novel species closely related to $F$. buharicum, a malvaceous pathogen of kenaf (H. cannabinus) and cotton (Gossypium sp.). DNA sequences generated in the present study were deposited in GenBank as KX302912 to KX302935. The NEXUS and tree file were accessioned in TreeBASE as S19369 and Tr96424, respectively.

\section{Results}

Pathogenicity assays. Some wilt, root, and crown rot symptoms were observed on all of the experimental plants inoculated with the H. moscheutos pathogen, Fusarium sp. NRRL 66179, 66182, or 66184 in both experiments (Fig. 1 and 2A). However, disease symptoms were not observed on the mock-inoculated negative control (Fig. 2B). Colonies that grew from the advancing margins of stem lesions on $1 / 2 \mathrm{~V} 8$ agar were morphologically identical to those used as inoculum; they were identified as the novel, undescribed Fusarium sp. by sequence analysis of the TEF 1 region (i.e., $100 \%$ match; data not shown).

Statistical analysis. ANOVA, $t$ tests, and GLM pairwise comparisons grouped by treatment, using lesion diameter as the dependent variable, yielded $P=0.000$ for inoculated treatments versus controls in all tests. Differences between treatments (isolates) under GLM were significant only in the first experiment. $P$ values for $t$ tests between treatments (isolates) and controls indicated that treatments and controls differed, thereby supporting pathogenicity of each isolate. However, the paired comparisons between treatments (isolates) conducted with GLM, when repeated, did not consistently result in $P \leq 0.05$ for any given pair; thus, there was no statistical support for differences in aggressiveness (virulence).

Identification of fungal isolates via phylogenetic analysis. In an attempt to identify the six strains isolated from symptomatic $H$. moscheutos stem and root tissue (Table 1), nucleotide sequence data were obtained from portions of $T E F 1, R P B 1$, and $R P B 2$ and used to conduct BLASTn queries of the National Center for Biotechnology Information (NCBI) GenBank, and Fusarium MLST (http://www.cbs. knaw.nl). Because the six strains shared identical TEF1, RPB1, and $R P B 2$ alleles, suggesting that they might represent clones, only sequences of NRRL 66179 were used to conduct BLASTn searches

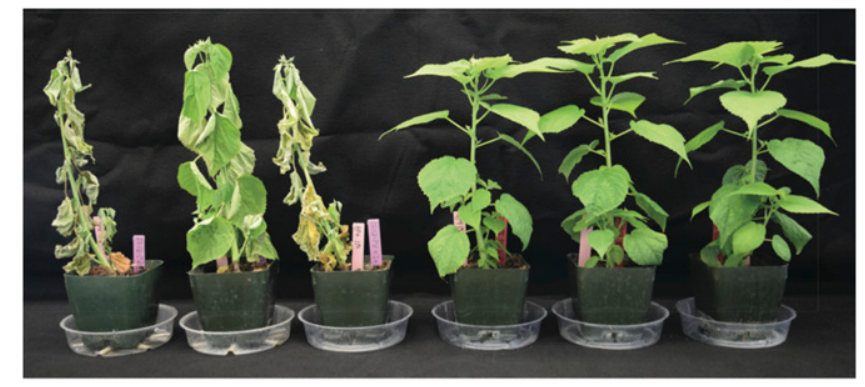

Fig. 1. Hibiscus moscheutos Luna Rose 2.5 weeks after three plants to the left were inoculated with Fusarium sp. isolate 2013-63 (NRRL 66182) and three plants to the right were inoculated with sterile distilled water. of the two web-accessible databases. Searches using the partial $T E F 1$ sequence as the query failed to identify any accessions producing significant alignments. However, searches of NCBI conducted with the partial $R P B 1$ and $R P B 2$ sequence data identified sequences of $F$. buharicum NRRL 13371 (JX171449 and JX171563) and F. sublunatum NRRL 13384 (JX171541 and JX171565) as the two best matches, with 93 and $90 \%$ identity, respectively. To obtain a definitive identification, the partial TEF1, RPB1, and $R P B 2$ sequence data obtained from the six $H$. moscheutos strains were aligned with those of closely related species within the $F$. buharicum, F. torreyae, and F. lateritium species complexes, based on our current understanding of phyletic relationships within the genus (O'Donnell et al. 2013), and analyzed phylogenetically using ML and MP methods. Analyses of the three individual partitions, in which the gene trees were midpoint rooted, indicated that the Hibiscus pathogen was nested within the $F$. buharicum species complex (FBSC) (MLIMP bootstrap support $[\mathrm{BS}]=98$ to $100 \%$ ) and closely related to $F$. buharicum (ML-BS\MP-BS $=89$ to $100 \%$ ) (Fig. 3A to C). An identical topology was obtained when the partial $R P B 1+R P B 2$ data were analyzed as a combined dataset and the phylogeny was rooted on sequences of $F$. buxicola and $F$. cyanostomum (Fig. 3D), based on more inclusive analyses (O'Donnell et al. 2013). The FBSC was strongly supported as sister to a clade comprising members of the $F$. lateritium and $F$. torreyae species complexes (Fig. 3A to D), which are primarily canker-inducing tree pathogens (Smith et al. 2011; Zhou et al. 2016).

\section{Discussion}

Pathogenicity experiments and multilocus molecular phylogenetics were used in the present study to characterize a novel Fusarium sp. responsible for a vascular wilt and crown and root rot of several H. moscheutos cultivars in a Washington State landscape planting. Results of the pathogenicity experiments show that the vascular wilt, root, and crown rot disease of the H. moscheutos cultivars in the Washington State landscape planting was caused by a novel Fusarium sp. closely related to two fusaria that are also pathogens of malvaceous hosts, $F$. buharicum and an undescribed species. The disease symptoms noted here are remarkably similar to those reported for $F$. buharicum on kenaf (Gerlach and Scharif 1970; Scharif and Akhavizadegan 1967). Both pathogens induce wilt together with root, crown, and stem rot on their respective hosts and blackening of the stem base, upon which abundant salmon-colored sporodochia were formed.

The Hibiscus pathogen was strongly supported by ML and MP bootstrapping as a genealogically exclusive species lineage (Taylor et al. 2000) closely related to $F$. buharicum, another malvaceous pathogen within the FBSC. Although partial TEF1 sequence data are the most widely used region to identify fusaria via BLASTn queries of



Fig. 2. Stem base of Hibiscus moscheutos. A, Two and one-half weeks after it was inoculated with Fusarium sp. isolate 2013-63 (NRRL 66182), showing canker with salmon-colored sporodochia. B, Asymptomatic negative control. 
GenBank, Fusarium-ID, or Fusarium MLST (Geiser et al. 2004; O'Donnell et al. 2010), we discovered that TEF1 sequences from members of the FBSC were not represented in these web-accessible databases. This finding highlights the need for a concerted effort to populate these databases with reference $T E F 1, R P B 1$, and $R P B 2$ sequences for all of the species complexes and monotypic lineages within Fusarium to facilitate identification of unknowns via the Internet.

Booth (1971) and Gerlach and Nirenberg (1982) accepted the placement of $F$. buharicum within the morphologically defined
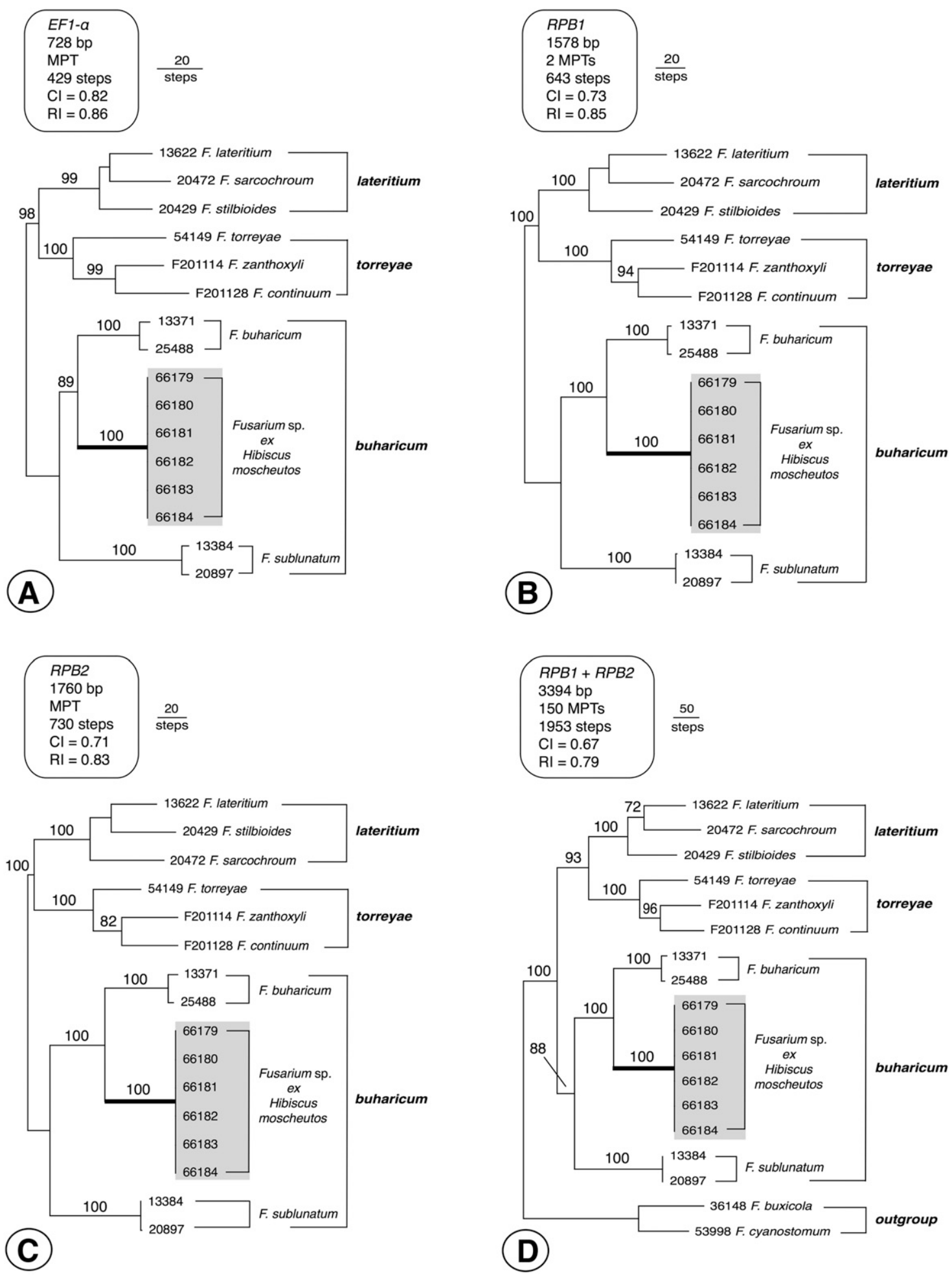

Fig. 3. A to C, Maximum-parsimony (MP) phylograms inferred from portions of three phylogenetically informative protein-coding genes, which were rooted by the midpoint method. $\mathrm{EF} 1-\alpha=$ translation elongation factor 1- $\alpha ; R P B 1$ and $R P B 2=$ DNA-directed RNA polymerase II largest and second-largest subunits, respectively; MPT = most-parsimonious tree; $\mathrm{Cl}=$ consistency index; and $\mathrm{RI}=$ retention index; $\mathrm{D}$, Phylogram inferred from the combined $R P B 1+R P B 2$ dataset rooted on outgroup sequences of Fusarium buxicola and $F$. cyanostomum. Note that strains of the novel Fusarium sp. pathogenic to Hibiscus moscheutos share identical TEF1, RPB1, and RPB2 alleles and that it is strongly supported as a genealogically exclusive lineage (maximum-likelihood [ML] bootstrap [BS]MP-BS $=100 \%$ ) within the $F$. buharicum species complex. This complex is sister to a clade comprising the $F$. lateritium and $F$. torreyae species complexes. The number above internodes represents ML-BS support based on 1,000 pseudoreplicates of the data. MP-BS is not indicated because it differed from the ML-BS value by $\leq 5 \%$. 
section Discolor. However, because molecular phylogenetic analyses have revealed that the sectional classification of Fusarium is largely artificial (Gräfenhan et al. 2011; O'Donnell et al. 2013), including that of section Discolor, we advocate referring to the genealogically exclusive lineages as species complexes. Currently, only two isolates of F. buharicum are housed in publically accessible culture collections and they include NRRL 13371 (= FRC R-4955 = CBS $796.70=$ DSM 62165) from stem lesions of kenaf (H. cannabinus L.) in Iran (Gerlach and Scharif 1970) and NRRL 25488 (= CBS 178.35 = DSM 62166) from crown (collar) rot of cotton (Gossypium sp.) in Russia and Uzbekistan (Gerlach and Nirenberg 1982). In addition to $F$. buharicum and the Fusarium sp. reported here from $H$. moscheutos, a closely related, undescribed species within the FBSC appears to be pathogenic to several malvaceous weeds in North America, including velvetleaf (Abutilon theophrasti Medik.), spurred anoda (Anoda crisata (L.) Schltdl.), and prickly sida (Sida spinosa L.) (unpublished data). This finding suggests that these three fusaria may have evolved some host specialization on members of the Malvaceae.

Although we did not find any reports of Fusarium spp. causing disease of H. moscheutos (Farr et al. 1989; Jones and Benson 2001), a plant that is native to North America (Small 2004), it is possible that this pathogen might have been misidentified in the phytopathological literature. Therefore, future surveys of this pathogen are needed to assess its genetic diversity and to elucidate its area of endemism, host range, and epidemiology so that proactive measures can be taken to minimize its impact on the ornamental industry.

\section{Acknowledgments}

We thank D. Ayling for technical assistance.

\section{Literature Cited}

Booth, C. 1971. The Genus Fusarium. Commonwealth Mycological Institute, Kew, Surrey, UK.

Boyd, D. W., and Cheatham, C. L. 2004. Evaluation of twelve genotypes of Hibiscus for resistance to hibiscus sawfly, Atomacera decepta Rohwer (Hymenoptera: Argidae). J. Environ. Hortic. 22:170-172.

Crespo, M., Arrebola, E., Cazorla, F. M., Maymon, M., Freeman, S., Aoki, T., O'Donnell, K., Torés, J. A., and de Vicente, A. 2016. Analysis of genetic diversity of Fusarium tupiense, the main causal agent of mango malformation disease in southern Spain. Plant Dis. 100:276-286.

Edgar, R. C. 2004. MUSCLE: Multiple sequence alignment with high accuracy and high throughput. Nucleic Acids Res. 32:1792-1797.

Environment Canada. 2013. Management Plan for the Swamp Rose-mallow (Hibiscus moscheutos) in Canada. Species at Risk Act Management Plan Series. Environment Canada, Ottawa, ON, Canada.

Farr, D. F., Bills, G. F., Chamuris, G. P., and Rossman, A. Y. 1989. Fungi on Plants and Plant Products in the United States. American Phytopathological Society, St. Paul, MN.

Geiser, D. M., Jimenez-Gasco, M. M., Kang, S., Makalowska, I., Veeraraghavan, N., Ward, T. J., Zhang, N., Kuldau, G. A., and O'Donnell, K. 2004. FUSARIUM-ID v. 1.0: A DNA sequence database for identifying Fusarium. Eur. J. Plant Pathol. $110: 473-479$.
Gerlach, W., and Nirenberg, H. 1982. The genus Fusarium-A pictorial atlas. Mitt. Biol. Bundesanst. Land-Forstwirtsch. Berlin-Dahlem 209:1-406.

Gerlach, W., and Scharif, G. 1970. Der Erreger einer Fußkrankheit an Hibiscus cannabinus in Iran-Fusarium buharicum Jaczewski. Phytopathol. Z. 68: 323-333.

Gräfenhan, T., Schroers, H.-J., Nirenberg, H. I., and Seifert, K. A. 2011. An overview of the taxonomy, phylogeny, and typification of nectriaceous fungi in Cosmospora, Acremonium, Fusarium, Stilbella, and Volutella. Stud. Mycol. 68:79-113.

Hunter-Cario, L. 2007. Propagation protocol for crimsoneyed rosemallow Hibiscus moscheutos L. (Malvaceae). Native Plants 8:65-68.

Jones, R. K., and Benson, D. M. 2001. Diseases of Woody Ornamentals and Trees in Nurseries. American Phytopathological Society, St. Paul.

Klips, R. A., Sweeny, P. M., Bauman, E. K. F., and Snow, A. A. 2005. Temporal and geographic variation in predispersal seed predation on Hibiscus moscheutos L. (Malvaceae) in Ohio and Maryland, USA. Am. Midl. Nat. 154:286-295.

Kudoh, H., and Whigham, D. F. 2001. A genetic analysis of hydrologically dispersed seeds of Hibiscus moscheutos (Malvaceae). Am. J. Bot. 88: 588-593.

O’Donnell, K., Cigelnik, E., and Nirenberg, H. I. 1998. Molecular systematics and phylogeography of the Gibberella fujikuroi species complex. Mycologia 90: 465-493.

O’Donnell, K., Rooney, A. P., Proctor, R. H., Brown, D. W., McCormick, S. P., Ward, T. J., Frandsen, R. J. N., Lysøe, E., Rehner, S. A., Aoki, T., Robert, V. A. R. G., Crous, P. W., Groenewald, J. Z., Kang, S., and Geiser, D. M. 2013. Phylogenetic analyses of $R P B 1$ and $R P B 2$ support a middle Cretaceous origin for a clade comprising all agriculturally and medically important fusaria. Fungal Genet. Biol. 52:20-31.

O’Donnell, K., Sutton, D. A., Rinaldi, M. G., Sarver, B. A. J., Balajee, S. A., Schroers, H., Summerbell, R. C., Robert, V. A. R. G., Crous, P. W., Zhang, N., Aoki, T., Jung, K., Park, J., Lee, Y., Kang, S., Park, B., and Geiser, D. M. 2010. Internet-accessible DNA sequence database for identifying fusaria from human and animal infections. J. Clin. Microbiol. 48:3708-3718.

Scharif, G., and Akhavizadegan, J. 1967. Fusarium foot rot of kenaf (Hibiscus cannabinus L.) in Iran. Entomol. Phytopathol. Appl. 26:1-17.

Small, R. L. 2004. Phylogeny of Hibiscus sect. Muenchhusia (Malvaceae) based on chloroplast $r p L 16$ and $n d h F$, and nuclear ITS and GBSSI sequences. Syst. Bot. 29:385-392.

Smith, J. A., O’Donnell, K., Mount, L. L., Shin, K., Peacock, K., Trulock, A., Cruse-Sanders, J., and Determann, R. 2011. A novel Fusarium species causes a canker disease of the critically endangered conifer, Torreya taxifolia. Plant Dis. 95:633-639.

Stevens, R. B., ed. 1974. Mycology Guidebook. University of Washington Press, Seattle.

Swofford, D. L. 2003. PAUP*. Phylogenetic Analysis Using Parsimony (*and other methods), version 4.0b10. Sinauer Associates, Sunderland, MA

Taylor, J. W., Jacobson, D. J., Kroken, S., Kasuga, T., Geiser, D. M., Hibbett, D. S., and Fisher, M. C. 2000. Phylogenetic species recognition and species concepts in fungi. Fungal Genet. Biol. 31:21-32.

Winters, H. F. 1970. Our hardy Hibiscus species as ornamentals. Econ. Bot. 24 $155-164$

Zhou, X., O'Donnell, K., Aoki, T., Smith, J., Kasson, M. T., and Cao, Z.-M. 2016. Two novel Fusarium species that cause canker disease of prickly ash (Zanthoxylum bungeanum) in northern China form a novel clade with Fusarium torreyae. Mycologia 108:668-681.

Zwickl, D. J. 2006. Genetic algorithm approaches for the phylogenetic analysis of large biological sequence datasets under the maximum likelihood criterion Ph.D. dissertation, The University of Texas Press, Austin. 